\title{
Effect of orally administered dipterinyl calcium pentahydrate on oral glucose tolerance in diet-induced obese mice
}

This article was published in the following Dove Press journal: Diabetes, Metabolic Syndrome and Obesity:Targets and Therapy 23 February 2012

Number of times this article has been viewed

\section{Svetlana E Nikoulina' \\ Dietmar Fuchs ${ }^{2}$ \\ Phillip Moheno'}

'SanRx Pharmaceuticals, Inc, La Jolla, CA, USA; ${ }^{2}$ Division of Biological Chemistry, Biocenter, Innsbruck Medical University, Innsbruck, Austria

Correspondence: Phillip Moheno SanRx Pharmaceuticals, Inc, 603 Colima Street, La Jolla, CA 92037-8032, USA

$\mathrm{Tel}+\mathrm{I} 8583449778$

Fax +l 8584546134

Email phil.moheno@sanrx.com

\begin{abstract}
Calcium pterins have been shown to be significant immunotherapeutic agents in models of breast cancer, hepatitis B, and tuberculosis (Bacillus Calmette-Guérin mycobacteria). These compunds modulate the immuno-enzyme indoleamine 2,3-dioxygenase (IDO) and the blood levels of several identified inflammatory cytokines. Recent research into the pathology of diabetes implicates inflammatory factors in the progression of the disease, leading the authors to study its possible control by one of the calcium pterins, dipterinyl calcium pentahydrate (DCP). The investigators tested DCP as a novel therapeutic for type 2 diabetes. Female C57BL/6 J mice with diet-induced obesity were fed a high-fat diet and were administered DCP in $0.4 \%$ carboxymethylcellulose for 21 days. Blood glucose was followed during the dosing period, and an oral glucose tolerance test (OGTT) was carried out on day 21. Measurements of plasma indoleamine 2,3-dioxygenase metabolites (tryptophan and kynurenine) and certain cytokines and chemokines were also taken. DCP $7 \mathrm{mg} / \mathrm{kg} /$ day reduced OGTT area under the curve (OGTT/ AUC) by $50 \%(P<0.05)$. A significant multivariate regression $\left(P=0.013 ; \mathrm{R}^{2}=0.571\right)$ of OGTT/ AUC was derived from DCP dosage and plasma Trp. Elevated plasma Trp concentration, likely from heterogeneity in diet and/or indoleamine 2,3-dioxygenase activity, was found to correlate with higher OGTT/AUC diabetic measures, possibly via inhibition of histamine degradation. In conclusion, an optimum dose of DCP $7 \mathrm{mg} / \mathrm{kg} /$ day significantly improved the OGTT diabetic state in these female diet-induced obese mice.
\end{abstract}

Keywords: diabetes, immunotherapy, oral glucose tolerance test, tryptophan, kynurenine

\section{Introduction}

Dipterinyl calcium pentahydrate (DCP) is a new molecular entity, the structure of which is based upon the endogenous substance pterin, and it works through a novel immunomodulatory mechanism. DCP has shown antitumor efficacy in mouse models of breast cancer ${ }^{1}$ and antiviral activity in transgenic mice with hepatitis B virus, ${ }^{2}$ as well as antimycobacterial activity in an in vitro model of tuberculosis (Bacille Calmette-Guérin). ${ }^{3}$ Preclinical studies have also shown that DCP works through a broad immunomodulatory mechanism involving a key immunoinhibitory enzyme, indoleamine 2,3-dioxygenase (IDO), which DCP appears to modulate to a "homeostatic" level. DCP inhibits IDO in some systems ${ }^{1-3}$ and promotes it in others, ${ }^{3}$ including the diet-induced obesity (DIO) model, as reported here. DCP also increases the plasma cytokines interleukin (IL)-12 and IL-4, ${ }^{4}$ and chemokine granulocyte-macrophage colony-stimulating factor, ${ }^{2}$ while decreasing IL- $6{ }^{4}$ and monocyte chemoattractant protein- $1 .{ }^{2}$ DCP potentiated monocyte antimycobacterial activity by induction of the $\mathrm{CC}$ chemokine macrophage inflammatory protein-1 beta, and inducible nitric oxide synthase $2 .^{3}$ 
Emerging literature ${ }^{5,6}$ suggests that inflammation, as evaluated by high inflammatory cytokine levels and other inflammatory markers, may represent a basic cause and consequence of obesity, type 2 diabetes, and comorbidities. Modulation of the levels of anti-inflammatory and proinflammatory cytokines may be an important strategy of therapeutic intervention in the treatment of type 2 diabetes and metabolic disease. The authors hypothesized that oral administration of DCP can improve glucose tolerance by normalizing the levels of proinflammatory cytokines, which are elevated in obesity and type 2 diabetes. Effects on glucose tolerance and other measures in vivo were determined in mice fed a high-fat diet to induce obesity and insulin resistance. DCP was found to significantly improve oral glucose tolerance, as determined by 2-hour area under curve (AUC) comparisons.

\section{Methods}

Twenty-four female diet-induced obese (DIO) C57BL/6J mice $^{7}$ (000664, B6; The Jackson Laboratory-West, Sacramento, CA) were used because they were presumed to have higher levels of IDO than males, based upon an earlier study. ${ }^{2}$ The mice were fed ad libitum a high-fat diet (D12492i, $60 \mathrm{kcal} \%$ fat; Research Diets Inc, New Brunswick, NJ) from 6 to 18 weeks of age. For 21 days afterwards, the test article, DCP in $0.4 \%$ carboxymethylcellulose, was administered daily by oral gavage at $0,7,21$,
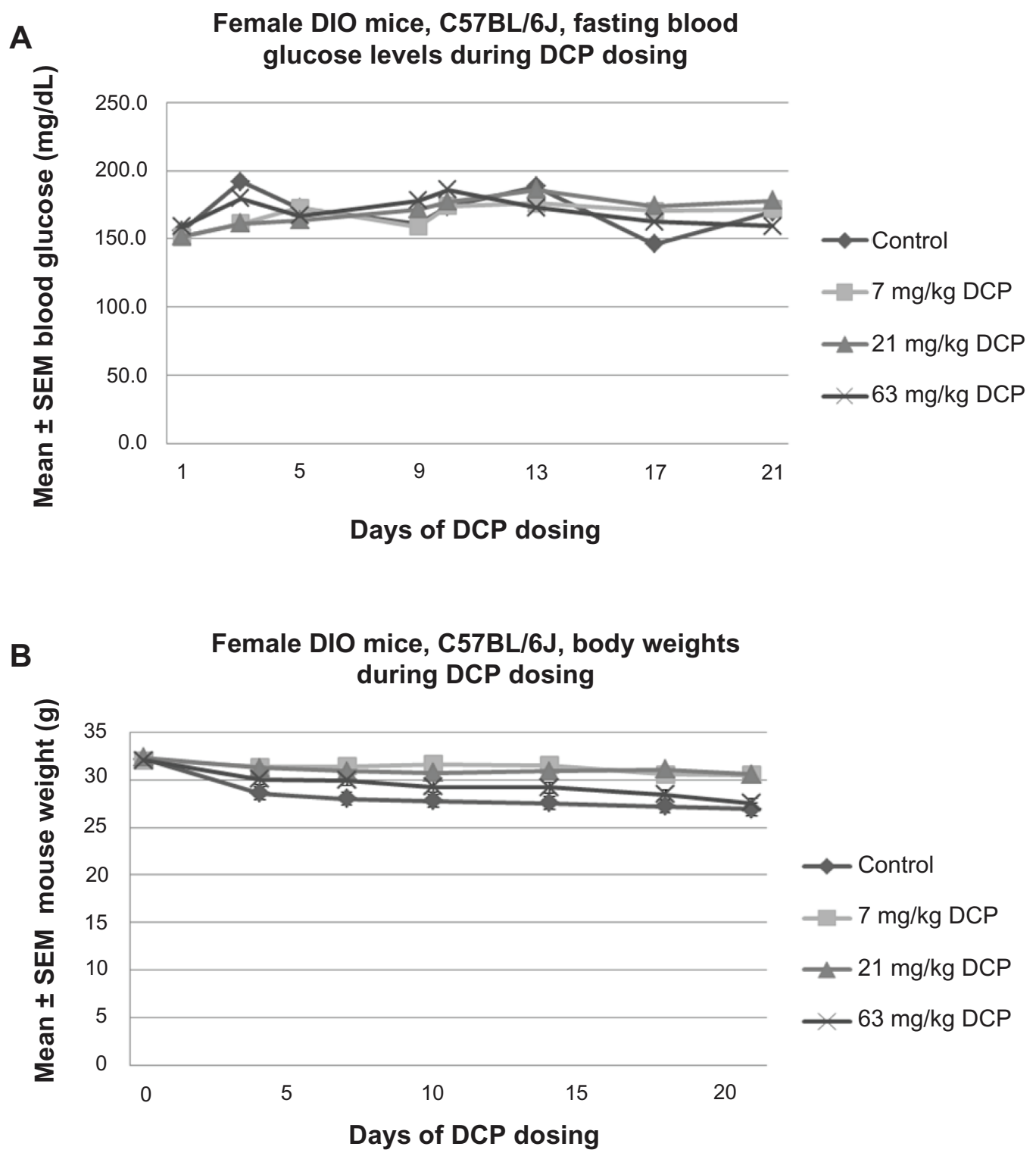

Figure I (A) fasting blood glucose levels and (B) body weights of female diet-induced obese (DIO) C57BL/6 J mice during the 2 I-day dipterinyl calcium pentahydrate (DCP) dosing period. The mice were divided into four treatment groups of DCP $0,7,21$, or $63 \mathrm{mg} / \mathrm{kg} /$ day.

Abbreviation: SEM, standard error of the mean. 
or $63 \mathrm{mg} / \mathrm{kg} /$ day to four groups of six mice each. During the DCP gavaging period three mice were lost because of gavaging trauma: one control and two from the $63 \mathrm{mg} / \mathrm{kg} /$ day group. Two of the plasma samples collected after DCP dosing were inadvertently not labeled and were therefore excluded from the analyses: one from the $21 \mathrm{mg} / \mathrm{kg} / \mathrm{day}$ group and one from the $63 \mathrm{mg} / \mathrm{kg} /$ day.

Blood glucose measurements were taken from fasted animals twice weekly as follows:

1. Animals were fasted for 6 hours prior to blood collection.

2. Blood (approximately $10-20 \mu \mathrm{L}$ ) was collected via tail snip. The scab was removed for subsequent blood sampling, until $2 \mathrm{~mm}$ of the tail tip was removed. Additional bleeds were then done via tail pricks (ie, sticking the vein or artery with a needle) from all animals, beginning just prior to group assignment. Blood glucose was measured using the OneTouch ${ }^{\circledR}$ Ultra $^{\circledR} 2$ blood glucose monitoring system (LifeScan, Inc, Milpitas, CA).

3. During the 21-day DCP dosing period, blood was collected 2 hours post dose on days 1, 3, 5, 9, 10, 13, 17, and 21 .
4. On day 21 after DCP administration, an oral glucose tolerance test (OGTT) was carried out measuring prechallenge blood glucose, and then at 30,60, 90, and 120 minutes post challenge with glucose $2 \mathrm{~g} / \mathrm{kg}$.

Plasma samples were collected by cardiac puncture on day 21 after DCP administration. The plasma IDO metabolites, tryptophan (Trp) and kynurenine (Kyn), were measured by high-performance liquid chromatography. ${ }^{8}$ EMD Millipore (St Charles, MO) measured the following cytokines and chemokines using a 96-well plate assay (Mouse Cytokine/Chemokine Magnetic Bead Panel Kit, \#MCYTOMAG-70 K; Millipore Corporation): granulocyte-macrophage colony-stimulating factor, interferon gamma, IL-1 alpha, IL-1 beta, IL-4, IL-6, IL-10, IL-12(p40), IL-12(p70), IL-13, monocyte chemoattractant protein-1, RANTES (regulated on activation, normal $\mathrm{T}$ cell expressed and secreted), and tumor necrosis factor alpha. Reported precisions for the overnight protocol for these cytokines and chemokines are intra-assay percent coefficient of variation $\leq 4.9 \%$ and inter-assay percent coefficient of variation $\leq 12.4 \%$. Plasma insulin and other glucose metabolism regulator levels were not determined for this pilot study.

Table I One-way analyses of variance of oral glucose (glu) tolerance test area under the curve (OGTT/AUC); plasma indoleamine 2,3-dioxygenase metabolites tryptophan (Trp), kynurenine (Kyn), and calculated Kyn/Trp ratio; and certain cytokines/chemokines

\begin{tabular}{|c|c|c|c|c|}
\hline $\begin{array}{l}\text { Mean } \pm \text { SEM } \\
(N=19)\end{array}$ & $\begin{array}{l}\text { DCP } 0 \mathrm{mg} / \mathrm{kg} / \mathrm{day} \\
(\mathrm{n}=5)\end{array}$ & $\begin{array}{l}\text { DCP } 7 \mathrm{mg} / \mathrm{kg} / \mathrm{day} \\
(\mathrm{n}=6)\end{array}$ & $\begin{array}{l}\text { DCP } 21 \mathrm{mg} / \mathrm{kg} / \mathrm{day} \\
(\mathrm{n}=5)\end{array}$ & $\begin{array}{l}\text { DCP } 63 \mathrm{mg} / \mathrm{kg} / \mathrm{day} \\
(\mathrm{n}=3)\end{array}$ \\
\hline OGTT/AUC $\mathrm{mg} \cdot$ minute/dL* & $5218 \pm 905$ & $2632^{\dagger} \pm 517$ & $4085 \pm 600$ & $5868 \pm 831$ \\
\hline 0 -minute glu (mg/dL) & $170 \pm 15$ & $172 \pm 20$ & $183 \pm 11$ & $162 \pm 17$ \\
\hline 30 -minute glu $(\mathrm{mg} / \mathrm{dL})^{* * * *}$ & $233 \pm 11$ & $207 \pm 11$ & $277^{\dagger} \pm 19$ & $312^{t+t} \pm 7.8$ \\
\hline 60-minute glu (mg/dL) & $200 \pm 18$ & $201 \pm 17$ & $211 \pm 15$ & $211 \pm 7.5$ \\
\hline 90-minute glu $(\mathrm{mg} / \mathrm{dL})^{* *}$ & $241 \pm 15$ & $178^{+\dagger} \pm 15$ & $163^{t+} \pm 7.7$ & $192^{\dagger} \pm 18$ \\
\hline I20-minute glu (mg/dL) & $162 \pm 13$ & $159 \pm 12$ & $162 \pm 6.3$ & $183 \pm 15$ \\
\hline $\operatorname{Trp}(\mu \mathrm{M})$ & $110 \pm 14$ & $110 \pm 9.0$ & $119 \pm 12$ & $122 \pm 5.0$ \\
\hline Kyn $(\mu M)^{* *}$ & $0.90 \pm 0.14$ & $0.96 \pm 0.10$ & $1.00 \pm 0.19$ & $1.84^{\dagger \dagger} \pm 0.25$ \\
\hline $\operatorname{Kyn} / \operatorname{Trp}(\mu M / m M)^{*}$ & $8.34 \pm 1.0$ & $8.92 \pm 0.87$ & $8.52 \pm 1.3$ & $15.13^{\dagger} \pm 2.0$ \\
\hline GM-CSF (pg/mL) & $<160$ & $<160$ & $<160$ & $192 \pm 32$ \\
\hline $\mathrm{IFN} \gamma(\mathrm{pg} / \mathrm{mL})$ & $<6.4$ & $<6.4$ & $<6.4$ & $15.7 \pm 9.3$ \\
\hline $\mathrm{IL}-\mathrm{I} \alpha(\mathrm{pg} / \mathrm{mL})$ & $467 \pm 258(4)$ & $496 \pm 170$ & $329 \pm 225$ & $348 \pm 197$ \\
\hline IL-I $\beta$ (pg/mL) & $34.7 \pm 2.7(4)$ & $<32.0$ & $41.6 \pm 8.5$ & $36.7 \pm 4.7$ \\
\hline IL-4 (pg/mL) & $7.76 \pm 1.4$ & $<6.4$ & $8.34 \pm 1.9$ & $<6.4$ \\
\hline IL-6 (pg/mL) & $59.2 \pm 8.8(4)$ & $24.7 \pm 9.6$ & $43.2 \pm 8.2(4)$ & $56.2 \pm 36.6$ \\
\hline IL-I0 (pg/mL) & $<32.0$ & $49.0 \pm 17.0$ & $32.8 \pm 0.76$ & $<32.0$ \\
\hline IL-I2(p40) (pg/mL) & $32.5 \pm 0.52(4)$ & $<32.0$ & $<32.0(4)$ & $<32.0$ \\
\hline IL-I2(p70) (pg/mL) & $69.0 \pm 31.5$ & $37.8 \pm 5.8$ & $123.6 \pm 80.5$ & $72.9 \pm 23.8$ \\
\hline IL-I 3 (pg/mL) & $197 \pm 23.1$ & $<160$ & $<160$ & $765 \pm 604.7$ \\
\hline MCP-I (pg/mL) & $70.8 \pm 26.1$ & $46.0 \pm 14.0$ & $49.6 \pm 13.3$ & $60.3 \pm 22.2$ \\
\hline RANTES (pg/mL) & $36.6 \pm 3.0(4)$ & $46.6 \pm 13.0$ & $33.1 \pm 1.1$ (3) & $49.5 \pm 17.5$ \\
\hline TNF $\alpha(p g / m L)$ & $12.0 \pm 5.3$ & $8.0 \pm 1.6$ & $10.2 \pm 2.4$ & $9.5 \pm 3.1$ \\
\hline
\end{tabular}

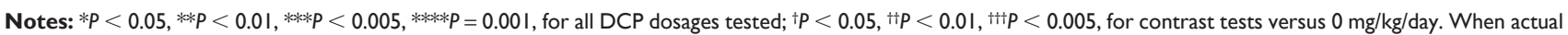
cell numbers are different these are given in parentheses.

Abbreviations: DCP, dipterinyl calcium pentahydrate; GM-CSF, granulocyte-macrophage colony-stimulating factor; IL, interleukin; IL-I $\alpha$, interleukin-I alpha; IL-I $\beta$, interleukin-I beta; IFN $\gamma$, interferon gamma; MCP-I, monocyte chemoattractant protein-I; RANTES, regulated on activation, normal T cell expressed and secreted; SEM, standard error of the mean; TNF $\alpha$, tumor necrosis factor alpha. 
Standard and repeated measures analysis of variance (ANOVA) and stepwise regression of the data were carried out using SPSS statistical software (GradPack, v 15.0, and v 19 for Windows; IBM Corporation, Armonk, NY). The test of homogeneity of variances was performed to determine the appropriate contrast tests to be used in the one-way ANOVAs. A $P$-value $<0.05$ was used to establish statistical significance.

\section{Results}

During the 21-day DCP dosing period there was no significant difference in blood glucose levels (Figure 1A) or body weights (Figure 1B) among the four treatment groups of DCP $0,7,21$, or $63 \mathrm{mg} / \mathrm{kg} /$ day, as determined by repeated measures ANOVA. The mice appeared to be hyperglycemic on the high-fat diet and not strikingly obese.

OGTT/AUC, plasma IDO metabolite, and cytokine/ chemokine measures using ANOVAs are given in Table 1, showing a significant $50 \%$ OGTT/AUC decrease for the mice treated with DCP $7 \mathrm{mg} / \mathrm{kg} /$ day $(P<0.05)$.

Four variables were identified by stepwise regression to yield the following OGTT/AUC linear regression $(P=0.013$; $\mathrm{R}^{2}=0.571$; see Table 2):

$$
\begin{aligned}
\text { OGTT/AUC }= & 0.009 \mathrm{DCP}^{3}+31.178 \mathrm{DCP}^{2} \\
& -574.513 \mathrm{DCP}+29.828 \mathrm{Trp} \\
& +1935.382,
\end{aligned}
$$

where DCP is the DCP dosage ( $\mathrm{mg} / \mathrm{kg} /$ day) and Trp is the plasma Trp concentration $(\mu \mathrm{M})$. From this equation it can be predicted that lowered plasma Trp levels are expected to improve (ie, decrease) OGTT/AUC measures.

\begin{tabular}{|c|c|c|c|c|c|}
\hline \multirow[t]{2}{*}{ Model } & \multicolumn{2}{|c|}{$\begin{array}{l}\text { Unstandardized } \\
\text { coefficients }\end{array}$} & \multirow{2}{*}{$\begin{array}{l}\text { Standardized } \\
\text { coefficients } \\
\text { Beta }\end{array}$} & \multicolumn{2}{|c|}{$t$-statistic $P$-value } \\
\hline & B & SE & & & \\
\hline (Constant) & 1935.382 & 1717.742 & NA & $\mathrm{I} .127$ & 0.279 \\
\hline $\mathrm{DCP}^{3}$ & 0.009 & 0.003 & 17.143 & 2.650 & 0.019 \\
\hline $\mathrm{DCP}^{2}$ & 31.178 & 11.113 & 23.797 & 2.806 & 0.014 \\
\hline DCP & -574.513 & 190.252 & -6.604 & -3.020 & 0.009 \\
\hline Trp & 29.828 & 14.533 & 0.369 & 2.052 & 0.059 \\
\hline
\end{tabular}

Table 2 Multivariate linear regression of oral glucose tolerance test area under the curve (OGTT/AUC) Coefficients ${ }^{a}$

Notes: aDependent variable is OGTT/AUC. Trp, Kyn, Kyn/Trp, granulocytemacrophage colony-stimulating factor, interferon gamma, IL-I alpha, IL-I beta, IL-4, IL-6, IL-I0, IL-12(P40), IL-12(p70), IL-13, monocyte chemoattractant protein-I, RANTES, and tumor necrosis factor alpha were tested by stepwise regression as predictors of OGTT/AUC. The selected variables were DCP ${ }^{3}, D^{2} P^{2}, D C P$, and Trp $(\mu \mathrm{M})$, where $\mathrm{DCP}$ is dosage $\left(\mathrm{mg} / \mathrm{kg} /\right.$ day); $P=0.013, \mathrm{R}^{2}=0.57 \mathrm{l}$ for the regression OGTT/AUC $=0.009 D^{2} P^{3}+31.178 D C P^{2}-574.513 \mathrm{DCP}+29.828 \operatorname{Trp}+1935.382$. Abbreviations: DCP, dipterinyl calcium pentahydrate; Kyn, kynurenine; NA, not applicable; RANTES, regulated on activation, normal T cell expressed and secreted; SE, standard error; Trp, tryptophan.
The DCP dose corresponding to the minimum (least diabetic) OGTT/AUC values can be determined by setting the first derivative of this equation equal to 0 :

$$
\begin{aligned}
0 & =\mathrm{d}(\text { OGTT } / \text { AUC }) \div \mathrm{d}(\mathrm{DCP}) \\
& =0.027 \mathrm{DCP}^{2}+62.356 \mathrm{DCP}-574.513,
\end{aligned}
$$

which can be solved for DCP by using the quadratic formula:

$$
\begin{aligned}
\text { DCP } & =\frac{62.356 \pm[(62.356)]^{2}-4(0.027)(-574.513)^{1 / 2}}{2(0.027)} \\
& =\frac{-62.356+62.852}{0.054}=0.496 / 0.054 \\
& =\text { DCP } 9.19 \mathrm{mg} / \mathrm{kg} / \text { day }
\end{aligned}
$$

This DCP dosage calculated from the regression equation corresponds very well with the experimentally derived value of $7 \mathrm{mg} / \mathrm{kg} /$ day from Table 1 for the antidiabetic dosage giving the minimum OGTT/AUC.

\section{Discussion}

From the values shown in Table 1 for Trp, Kyn, and the calculated $\mathrm{Kyn} / \mathrm{Trp}$ ratio, it appears that IDO activity is not involved with the antidiabetic OGTT/AUC minimum at DCP $7 \mathrm{mg} / \mathrm{kg} /$ day. Interestingly, the plasma IL-6 pattern shown in Table 1, although nonsignificant, resembles the significant $(P<0.05)$ OGTT/ AUC pattern, in that the lowest values for IL-6 and OGTT/AUC both correspond to a DCP dose of $7 \mathrm{mg} / \mathrm{kg} /$ day. Previous resear chers have called for investigation into the role of IL- 6 in diabetes types 1 and $2^{6}$ and its role in the immune system generally in type 2 diabetes. ${ }^{5}$

Of particular interest is the finding that plasma Trp enters into the significant $(P=0.013)$ multivariate regression predicting the OGTT/AUC response (Table 2). US Food and Drug Administration researchers ${ }^{9}$ have determined that elevated Trp levels can lead to increased formation of formate and indolyl metabolites, several of which inhibit the degradation of histamine, potentially leading to eosinophilia-myalgia syndrome and diabetes. ${ }^{10}$ In this regard, $98 \%$ of surveyed eosinophilia-myalgia syndrome patients from the United States reported having used L-Trp-containing products prior to the onset of illness at a median dosage of $1500 \mathrm{mg} /$ day. ${ }^{11}$ This human dose $(1500 \mathrm{mg} / 70 \mathrm{~kg}=21 \mathrm{mg} / \mathrm{kg})$ corresponds to a mouse dosage of $264 \mathrm{mg} / \mathrm{kg}$, based upon allometric scaling. The estimated corresponding mouse plasma/tissue level increase,

$$
\begin{aligned}
& 264 \mathrm{mg} / \mathrm{kg} \times(\operatorname{Trp~} \mathrm{mmoL} / \operatorname{Trp} 204 \mathrm{mg}) \times(\mathrm{kg} / 0.7 \mathrm{~L}) \\
& \quad=\operatorname{Trp} 1.85 \mathrm{mM},
\end{aligned}
$$


or, if not allometrically scaling,

$21 \mathrm{mg} / \mathrm{kg} \times(\operatorname{Trp} \mathrm{mmoL} / \operatorname{Trp} 204 \mathrm{mg}) \times(\mathrm{kg} / 0.7 \mathrm{~L})$

$=\operatorname{Trp} 0.15 \mathrm{mM}$,

which in either case substantially increases the DIO mouse plasma Trp levels beyond those shown in Table 1.

\section{Conclusion}

In conclusion, the authors find:

1. DCP significantly $(P<0.05)$ improves oral glucose tolerance at $7 \mathrm{mg} / \mathrm{kg} /$ day in female DIO mice.

2. A significant $(P=0.013)$ multiple regression, in terms of $\mathrm{DCP}^{3}, \mathrm{DCP}^{2}$, and DCP dosages, and plasma Trp levels, can be constructed, which explains $57 \%$ of the OGTT/ AUC variance in this measure of glucose tolerance in the DIO mice.

\section{Acknowledgments}

Phillip Moheno is grateful to Dr David Schubert of the Salk Institute for Biological Studies for his insight and discussions related to this study.

\section{Disclosures}

All the authors conducted the research. Phillip Moheno and Svetlana E Nikoulina performed the data analysis and wrote the manuscript. Phillip Moheno holds stock, and all authors hold stock options, in SanRx Pharmaceuticals, Inc, which has been assigned patent rights to DCP.

\section{References}

1. Moheno P, Pfleiderer W, DiPasquale AG, Rheingold AL, Fuchs D. Cytokine and IDO metabolite changes effected by calcium pterin during inhibition of MDA-MB-231 xenograph tumors in nude mice. Int J Pharm. 2008;355(1-2):238-248.

2. Moheno P, Morrey J, Fuchs D. Effect of dipterinyl calcium pentahydrate on hepatitis B virus replication in transgenic mice. J Transl Med. 2010;8:32.

3. Sakala IG, Blazevic A, Moheno P, Hoft DF. Dipterinyl calcium pentahydrate inhibits intracellular mycobacterial growth in human monocytes via the C-C chemokine MIP-1beta and nitric oxide. Unpublished manuscript; 2011.

4. Moheno P, Pfleiderer W, Fuchs D. Plasma cytokine concentration changes induced by the antitumor agents dipterinyl calcium pentahydrate (DCP) and related calcium pterins. Immunobiology. 2009;214(2):135-141.

5. Kolb H, Mandrup-Poulsen T. An immune origin of type 2 diabetes? Diabetologia. 2005;48(6):1038-1050.

6. Kristiansen OP, Mandrup-Poulsen T. Interleukin- 6 and diabetes: the good, the bad, or the indifferent? Diabetes. 2005;54 Suppl 2: S114-S124.

7. Gallou-Kabani C, Vigé A, Gross MS, et al. C57BL/6 J and A/J mice fed a high-fat diet delineate components of metabolic syndrome. Obesity (Silver Spring). 2007;15(8):1996-2005.

8. Widner B, Werner ER, Schennach H, Wachter H, Fuchs D. Simultaneous measurement of serum tryptophan and kynurenine by HPLC. Clin Chem. 1997;43(12):2424-2426.

9. Smith MJ, Garrett RH. A heretofore undisclosed crux of eosinophilia-myalgia syndrome: compromised histamine degradation. Inflamm Res. 2005;54(11):435-450.

10. Gill DS, Barradas MA, Fonseca VA, Dandona P. Plasma histamine concentrations are elevated in patients with diabetes mellitus and peripheral vascular disease. Metabolism. 1989;38(3):243-247.

11. Kaufman LD, Philen RM. Tryptophan: current status and future trends for oral administration. Drug Saf. 1993;8(2):89-98.

Diabetes, Metabolic Syndrome and Obesity: Targets and Therapy

Dovepress

\section{Publish your work in this journal}

Diabetes, Metabolic Syndrome and Obesity: Targets and Therapy is an international, peer-reviewed open-access journal committed to the rapid publication of the latest laboratory and clinical findings in the fields of diabetes, metabolic syndrome and obesity research. Original research, review, case reports, hypothesis formation, expert opinion and commentaries are all considered for publication. The manuscript management system is completely online and includes a very quick and fair peer-review system, which is all easy to use. Visit http://www.dovepress.com/testimonials.php to read real quotes from published authors. 